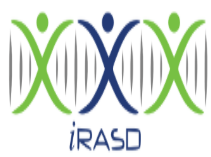

iRASD Journal of Management

Volume 3, Number 3, 2021, Pages 318 - 328

\title{
Impact of Online Recruitment on Organizational Attractiveness: An Experimental Study in the Context of Pakistan
}

\author{
Qamar Ali ${ }^{1}$, Muhammad Naveed Aslam², Sahar Hafeez ${ }^{3}$ \\ ${ }^{1}$ Lyallpur Business School, Government College University Faisalabad, Faisalabad, Pakistan. \\ Email: qamarali@gcuf.edu.pk \\ ${ }^{2}$ Lyallpur Business School, Government College University Faisalabad, Faisalabad, Pakistan. \\ Email: naveed37370@gmail.com \\ ${ }^{3}$ National University of Modern Languages, Islamabad, Pakistan. Email: sahar_hafeez@ymail.com
}

\section{ARTICLE INFO}

Article History:

Received:

Revised:

Accepted:

November 26,2021

December 28, 2021

December 28, 2021

Available Online: December 29, 2021

\section{Keywords:}

Online Recruitment

Website Features

Organizational Culture

Organizational Attractiveness

Intention to Apply (IA)

Pakistan

\begin{abstract}
The purpose of this study is to explore the aesthetical features of corporate recruitment websites, including the website design, style, and color, and to investigate their impact on organizational attractiveness and applicants' intention to apply. By doing so, the study also examines the effects of corporate websites on applicants' perception of the corporate culture and measures the mediating impact of perceptions of organizational culture on organizational attractiveness and applicants' intention to apply for the jobs in the context of Pakistan. The study is based on a laboratory experiment with three hundred undergraduate business students conducted at a university computer lab. Correlation, Independent T-test, One-way ANOVA, and Simple Linear Regression were applied to analyze variables using SPSS. The findings of this study support the hypothesis that website features have a significant positive impact on applicants' perceived organizational attractiveness. However, the website's design does not seem to impact applicants' intentions to apply for the job substantially. The regression analysis results also revealed that the perceived organizational culture partially mediates the relationship between website features and organizational attractiveness and fully mediates the relationship between website features and intentions to Apply.
\end{abstract}

(c) 2021 The Authors, Published by iRASD. This is an Open Access article under the Creative Common Attribution Non-Commercial 4.0

Corresponding Author's Email: qamarali@gcuf.edu.pk

\section{Introduction}

Online recruitment channels are now overcoming the traditional methods of recruitment. The key reason for the explosive growth of online recruiting is the twin benefits it offers (Kucherov \& Tsybova, 2021). It enhances the recruiters' efficiency by reaching a vast and diverse audience worldwide in less time and cost and enables the applicants to search for their desired jobs and build the career they want (Muduli \& Trivedi, 2020). Corporate websites are organizations' windows into the global electronic world. The online recruitment websites have a global reach, enabling the organizations to bring in applicants with wide skills, knowledge, and abilities. Such an inclination towards innovative technology in industry 4.0 also proves to be cost-effective for the organizations to seek a broad audience (Puncheva-Michelotti, Hudson, \& Jin, 2018).

Previous research demonstrates that the perceptions regarding the organizational culture are strongly affected by website development concerning the website design and content features (Acikgoz, 2019). Web-based technologies have expedited the recruitment process remarkably, thereby increasing efficiency. Apart from other benefits of web-based technologies, customized information as per the target audience and the website aesthetic 
properties are the two key aspects of distinguished importance. Customized information refers to the information tailored to individual job seekers in response to the information they initially provide about themselves and is consistent with the move toward customization that the marketing field has begun to embrace and calls to examine customized recruitment. Aesthetic aspects refer to features such as fonts, pictures, colors, Web page design features, etc., that can be incorporated into the job advertisement and the recruitment process (Banerjee \& Gupta, 2019).

The current study explores the aesthetics features, including the website design, style, and color and their impact on organizational attractiveness and applicants' intention to apply. It investigates the effects of corporate websites on applicants' perception of the corporate culture. It examines the impact of positive or negative perceptions of organizational culture on organizational attractiveness and applicants' intention to apply for vacant positions in Pakistan.

In the process, from the first advertisement encounter until the final decision to apply for the position, the formation of perception is very crucial. Signaling theory plays an important role in shaping applicants' behavior in the whole process (Chang \& Chin, 2018). It recommends that applicants depict assumptions about the organization based on peripheral cues gained from its website in the absence of other information about an organization. It mainly happens because applicants assume that these indications are representative of the whole organization.

Despite the increasing importance of internet recruitment and the recent research efforts, there remains a fundamental gap in the e-recruitment literature. Previous studies have largely examined the correlation among various recruitment websites features. However, only a few studies have empirically tested the relationship between individuals' impressions of the organization and its recruitment website content and underlying features (Ageeva, Foroudi, Melewar, Nguyen, \& Dennis, 2020). Also, most of the research is based only in developed countries, ignoring developing countries such as Pakistan. The practice of online recruitment is also becoming widely common and is being accepted in the culture of Pakistan. Despite the widespread growth, only little has been known about the websites' influence on the recruitment outcomes, calling for attention in this field. Therefore, this research actively tries to reduce that gap by empirically determining the applicant's behavioral effects on various website design features. Also, this study will be the addition to the field of recruitment literature in the developing regions as the basis of the internet usage framework varies from the developed nations. The experimental design method is used to achieve the objectives of this study. For this purpose, undergraduate students are approached randomly and asked to participate in the experiment organized in a university computer laboratory to participate in the investigation.

This research intends to examine the change in the perceptions of the applicant regarding the organization after visiting the respective organization's recruitment website by using an experimental design method. The study also tries to fill the existing gap in the literature in online recruitment and tries to extend the research from developed nations to developing countries. It also explores the effect of website design, style, and color features on the job seekers' perception of the recruiting organization's culture, job pursuit intentions, and organizational attractiveness.

\section{Literature Review \\ 2.1. Website Features}

Internet recruitment has many advantages over traditional recruitment methods both for the organization and the applicants. Due to its benefits, most organizations preferably use online recruitment to deliver information to prospective applicants (Ali, Sheikh, \& Latif, 2021). Research in the past has focused on traditional recruitment methods. However, very little research has focused on the new web-based recruitment programs and, in particular, the design features of the websites that will directly affect the potential workforce of a company. 
Cober, Brown, Keeping, and Levy (2004) have argued that technological advancements and innovations in website development potentially impact the recruitment process. They propose a conceptual model for job seekers' attractiveness and their reaction to applying website features such as aesthetics and playfulness using various propositions from previous literature. They believe a higher degree of aesthetics and playfulness leads to the potential applicants' more favorable initial effective reaction. The affective reaction is the initial spontaneous reaction evoked by the website's various features. Along with the other system features of the website, the initial affective behavior then plays a significant role in forming perceptions. Perception of usability and sentimental reactions work through two key mediating constructs, job seeker search behavior and website attitude, to predict applicant attraction. Further, the research also proposes that the corporate employment websites also serve as a tool for evaluating the person's organizational fit, affecting the individual's decision or intention to apply.

Phillip W Braddy, Meade, and Kroustalis (2006) find the impact of website design features and content on the impressions of job seekers regarding the organizational culture. They argue that professional recruitment websites provide the applicants with more diverse information, including related to the job and overall corporate culture, compared to traditional recruitment, which gives only specific information about just job descriptions. The third-party recruitment websites and job boards are also very specific in providing only job-related information. In contrast, professional organizational websites are identified as diverse sources of information regarding the corporate culture and values.

Philip W Braddy, Thompson, Wuensch, and Grossnickle (2003) study the effect of two website design features as navigational simplicity and text formatting on the prospective applicant evaluation of the recruitment advertisement and the hiring company regarding their culture and overall image. The additional research proves only the mediumlevel effect of these two design features on perception building and organizational attractiveness. Further, the results also show that the beauty of the web page affected respondents' perceptions of quality.

The organizations' recruitment image is the most important feature for internetbased recruitments. Therefore, it is more important to design the website to show a better recruitment image of the company. The recruitment image is followed by the next most important characteristic, i.e., web design and physical features. The feature of websites differentiates traditional methods of recruitments through job advertisements, brochures, and even websites with textual data (Coyle \& Thorson, 2001). These features provide users with even richer experiences while walking through the website.

Website success is significantly associated with navigation-related matters, downloads, and content response time (Agarwal \& Venkatesh, 2002). According to web credibility research from Stanford, $75 \%$ of users admit to making judgments about a company's credibility based on their website's design (Thompson, Braddy, \& Wuensch, 2008).

The website style is defined as the overall patterns for graphics and other content to make the overall outlook more attractive and catchier. In this digital era of rapid communication and technological breakthroughs, professional recruitment websites have become the primary source of getting the required information for potential candidates. However, it also works the other way around. Therefore, the organizations need to be more proactive in managing and successfully upgrading the website features and style as per the needs of applicants. The literature suggests a strong relationship between websites' quality, style, content, and potential applicants' attraction and interest. It also enhances the chances for job-seekers to apply for various job positions. In addition, the consumer literature suggests a strong correlation between the aesthetic properties of website design features and job-seekers attitudes, involvement, and intentions (Cober, Brown, Levy, Cober, \& Keeping, 2003).

The color appeal is usually defined as the degree to which the various colors used in the website are perceived as pleasing and appropriate. Various design features of the websites have significant impacts on the job seeker's perception formation, the attractiveness of the websites, and the organizational culture. The website color scheme is 
also an important determinant for building the website's trust and satisfaction, which can lead to positive perceptions regarding the corporate culture and the attractiveness of the viewer (Cyr, Head, \& Larios, 2010).

\subsection{Organizational Culture}

Phillip W Braddy et al. (2006) study the effect of website content features on the job-seekers perceptions of the organizational culture. Their study examines the impact of website features, including pictures, testimonials, corporate policies, awards, and certificates, on individuals' perceptions of the corporate culture. They used eight dimensions: innovation, outcome orientation, supportiveness, team orientation, diversity, decisiveness, aggressiveness, and attention to detail. It highlights the importance of transferring the organizational culture information and its effects on the individual's cultural perceptions and preferences and the person-organization (P-O) fit and attractiveness. The culture-specific competitive corporate awards being won by the organization strongly transmit the positive perceptions regarding the cultural characteristics of aggressiveness. Various website design and style features are useful elements in conveying strong cultural dimensions of interest for any prospective applicant. Asking for feedback and reviews regarding these website contents and features can help the organizations to build on the positive aspects, thus enhancing the organizational attractiveness and chances for application as fueled by individuals' enhanced interest.

Researchers have also examined the global corporate websites, the level of standardization being adapted by various organizations worldwide, and the differences that exist due to the organizational culture and values industry differences. It has been found that the content feature incorporated in the website has a major impact on the perceptions regarding the corporate culture (Robbins \& Stylianou, 2003). Among the other features and other variables discussed above, the type of communication media selected to interact with applicants also has a key effect on forming the perceptions regarding organizational culture and their intention to apply for the job. The medium that allows two-way communication and feedback is more persuasive in developing perceptions regarding the features and style components that affect organizational culture (Allen, Scotter, \& Otondo, 2004).

\subsection{Organizational Attractiveness}

The technological advancements in this era have accelerated the use of the internet and online technology more rapidly than ever, thus forcing the organizations both at a public and private level to adapt their various practices regarding recruitment and hiring to this technological change. As a result, job seekers' behavior is also affected due to the outlook and the content of recruitment websites. Therefore, researchers have studied the relation between the website content and the resulting attraction and the association between the website content and the user's intention to apply for a certain job position. The two dimensions being used for this purpose are the quality of the website content and its usability. The research proves that these dimensions significantly impact the user's behavior and intention to apply for the job position. It also lowers the voluntary turnover of the new hires. Researchers have recommended that governments move toward erecruitment by accepting that online job seekers are consumers of employment information rather than mere applicants that need to be screened (Selden \& Orenstein, 2011).

According to Mortensen (2011), an online job portal can be made more attractive by including original pictures of the office. Photos of a beautifully decorated, most professional workplace give an accurate perception of the workplace and make it easy for the applicant to decide whether they are willing to apply for this job or move to the next job advertisement. Organizations should add the most relevant and attractive aspects of a career in their online recruitment messages, such as highlighting incentives, bonuses, and fringe benefits. Moreover, choosing the most appropriate colors for the online advertisement makes the advertisement user-friendly. On the other hand, the use of workplace pictures helps the most suitable candidates make a quick decision about the job application. 
Organizational attractiveness is primarily affected by the usability features of the websites and the person-organizational fit. It highlights the importance of website navigational features and highlights the usefulness of the information being posted to develop better recruitment websites (Pfieffelmann, Wagner, \& Libkuman, 2010).

\subsection{Intentions to Apply}

Despite the extensive research in online recruitment and selection practices, only little is still known regarding the applicant's behavior and attitude towards online professional recruitment websites. Sylva and Mol (2009) explore various internal and external factors of online recruitment effectiveness. The user-friendliness of the recruitment website and the perceived efficiency in terms of time and efforts required to comprehend a job advertisement are the most important factors that form applicants' perceptions towards the organization and willingness to apply for the job. Also, the various website-related factors that include the perceptions vary based on users' cultural and personal differences. In contrast, savvy internet users consider online recruitment a more valuable and efficient process. In addition, the various HR strategies being mentioned on the corporate websites also play a significant part. They unintentionally affect the applicant's reactions, satisfaction level, and organizational attractiveness. Lastly, it is highly suggested that additional and concise (well directed to the specific determinants) research is much needed in the current area of online recruitment and the website development and the design features.

Attracting the right and competitive talent has remained one of the key challenges for organizations worldwide. The technology acceptance model provides significant insights into the individual behavior towards using the website and online portals. It also explains the various reasons behind the usage of information technology led by intrinsic and extrinsic motivations. Diverse literature and researches have considered the perceived usefulness and enjoyment as the key contributors to the intention and actual use of online websites, the ease of use, and other technical variables. In addition, the perceived organizational culture and attractiveness as led by the website design and content features also play a huge role in the intention to use and apply for various positions when talking specifically about recruitment websites. Also, the applicants are attracted and show interest in the organizations that provide the best $\mathrm{P}-\mathrm{O}$ fit, which means that the individuals are attracted to the organizations and are more motivated to apply to firms whose organizational culture and values reflect their personality traits. It is also observed that the fit between the characteristics of human resource systems in organizations and individual parts was an important determinant of job acceptance. Therefore, the organizations must be proactive in developing their website's design features and incorporate the various aesthetics and content elements to fulfill what users are looking for in a particular website. (Van der Heijden, 2003).

Scheu, Ryan, and Nona (1999) found that positive impressions of a recruiting website's design were associated with intentions to apply to that company. Research conducted by Sivertzen, Nilsen, and Olafsen (2013) suggests that website innovation, application value, and use of social media positively relate to corporate reputation, which is linked to intentions to apply for a job.

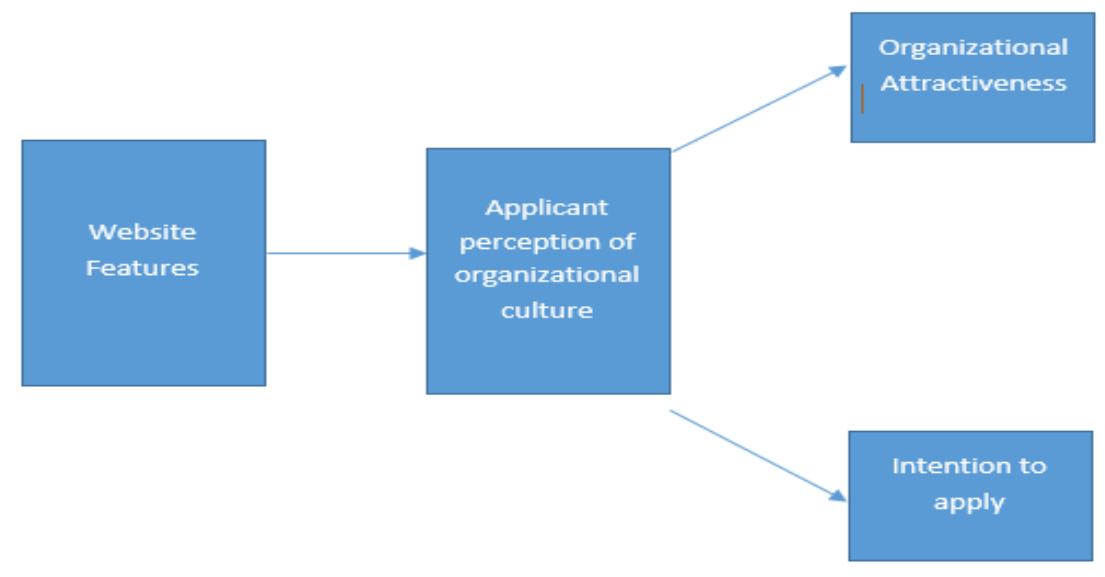




\subsection{Research Hypotheses}

H1: Website features of Website $B$ are perceived to be better than features of Website $A$.

H2: Organizational culture of website $B$ perceive better than the organizational culture of website A.

H3: Organization $B$ will be perceived to be more attractive than organization $A$

H4: Intention to apply for a job in organization B will be higher than those for organization A.

H5: Website features significantly impact applicant perception of organizational culture.

H6: Applicant perception of organizational culture positively and significantly impacts organizational attractiveness.

H7: Website features have a positive and significant impact on intentions to apply

H8: Applicant perception of organizational culture positively and significantly impacts intentions to apply.

H9: Applicant perception of organizational culture mediates the relationship between Website features and organizational attractiveness.

H10: Applicant perception of organizational culture mediates the relationship between Website features and intentions to apply.

\section{Methodology \\ 3.1. Design}

The study used the websites of two multinational companies operating in Pakistan for this experiment. Websites were different in features, one website was attractive in design and style, and the second website was simple in parts. The total number of participants was 300, of which 67 percent were males and 33 percent were females. The experiment was held in the university computer Lab as there was enough space and active internet service to access the companies' websites online. The websites contained a home page providing a brief introduction of the company and its numerous \& diverse subsidies. The website has a career page. Participants visit the career page for different jobs offered in various disciplines like business management, management information systems, Marketing, and Finance. Website 1 is a simple website assigned to Group A. Website 2, which is attractive in features, was assigned to Group B. Questionnaire was presented at the end of the website browsing exercise.

\subsection{Data Analysis}

A questionnaire designed on the five points Likert Scale was used to achieve the outcomes of this study. The study performed Cronbach Alpha, Correlation Coefficients, Oneway ANOVA, T-test, and Simple Linear Regression for data analysis. These tools have been used to know the significant relationship between independent and dependent variables.

\subsection{Measurement Instruments}

We measured applicants' perception of organizational culture using the five items adapted from O'Reilly III, Chatman, and Caldwell (1991) and measured organizational attractiveness with the three items adapted from Fisher, Ilgen, and Hoyer (1979). We used three items adapted from Aiman-Smith, Bauer, and Cable (2001) to measure participants' intentions to apply. 


\section{Results}

We tested all instruments for reliability using the Cronbach Alpha technique, which showed that all measurement instruments and the corresponding responses were valid: website features (.701), applicant perception of organizational culture (.747), organizational attractiveness (.816), and intention to apply (.702).

\section{Table 1}

Correlation Analysis

\begin{tabular}{|c|c|c|c|c|c|}
\hline & & WFTR & $\mathrm{OC}$ & IA & $\mathrm{OA}$ \\
\hline Website & Pearson Correlation & 1 & $.234 * *$ & .002 & $.212 * *$ \\
\hline \multirow[t]{2}{*}{ features } & Sig. (2-tailed) & & .000 & .978 & .000 \\
\hline & $\mathrm{N}$ & 300 & 300 & 300 & 300 \\
\hline \multirow{3}{*}{$\begin{array}{l}\text { Organizational } \\
\text { culture }\end{array}$} & Pearson Correlation & $.234^{* *}$ & 1 & $.122^{*}$ & $.282^{* *}$ \\
\hline & Sig. (2-tailed) & .000 & & .035 & .000 \\
\hline & $\mathrm{N}$ & 300 & 300 & 300 & 300 \\
\hline Intention to & Pearson Correlation & .002 & $.122^{*}$ & 1 & $.284^{* *}$ \\
\hline \multirow[t]{2}{*}{ Apply } & Sig. (2-tailed) & .978 & .035 & & .000 \\
\hline & $\mathrm{N}$ & 300 & 300 & 300 & 300 \\
\hline Organizational & Pearson Correlation & $.212^{* *}$ & $.282^{* *}$ & $.284^{* *}$ & 1 \\
\hline \multirow{2}{*}{ Attractiveness } & Sig. (2-tailed) & .000 & .000 & .000 & \\
\hline & & 300 & 300 & 300 & 300 \\
\hline
\end{tabular}

Table 1 represents the results of the Correlation analysis of website features. The calculation depicts that the website features have a strong and positive relation with applicant perception of organizational culture and organizational attractiveness but have no significant association with intentions to apply. The results of independent T-tests (Appendix 1-4) show that website $B$ features are perceived to be better than features of website A. The Mean value of group B (3.6707) is greater than the Mean value of group A (3.3573), which indicates that features of website $B$ are perceived better than those of website A. Culture of organization $B$ is perceived to be better than the culture of organization A. The Mean value of group B is 3.6147, and the Mean value of group A is 3.4080. Hence, it shows that group $B$ visited a more attractive company website with higher organizational attractiveness than group $A$. So, we will accept our hypothesis that the corporate culture of website $B$ is better than the organizational culture of website $A$.

Organization $B$ will be perceived to be more attractive than organization $A$. The mean value of group B is 3.7289, and group A has 3.3533. Hence, it implies that group B visited a comparatively more attractive company website as it shows higher organizational attractiveness than group A. So, by this result, we will accept the proposed hypothesis that organization $B$ will be perceived more attractive than organization $A$. Intentions to apply for a job in organization $B$ will be higher as compared to those for organization $A$. The mean value of group B is 3.8200 , and group A has 3.4133 . So, by this result, we will accept the proposed hypothesis that the intention to apply for a job in organization $B$ will be higher than those for organization A.

\subsection{Analysis of Variance (ANOVA)}

One-way ANOVA (Appendix 5) shows that the website features and applicant perception of organizational culture positively and significantly impact organizational attractiveness with a highly significant P-value .000.

The results show that the variable website features have an insignificant impact on intention to apply. Still, the organizational culture has a positive and significant effect on the intention to apply. 


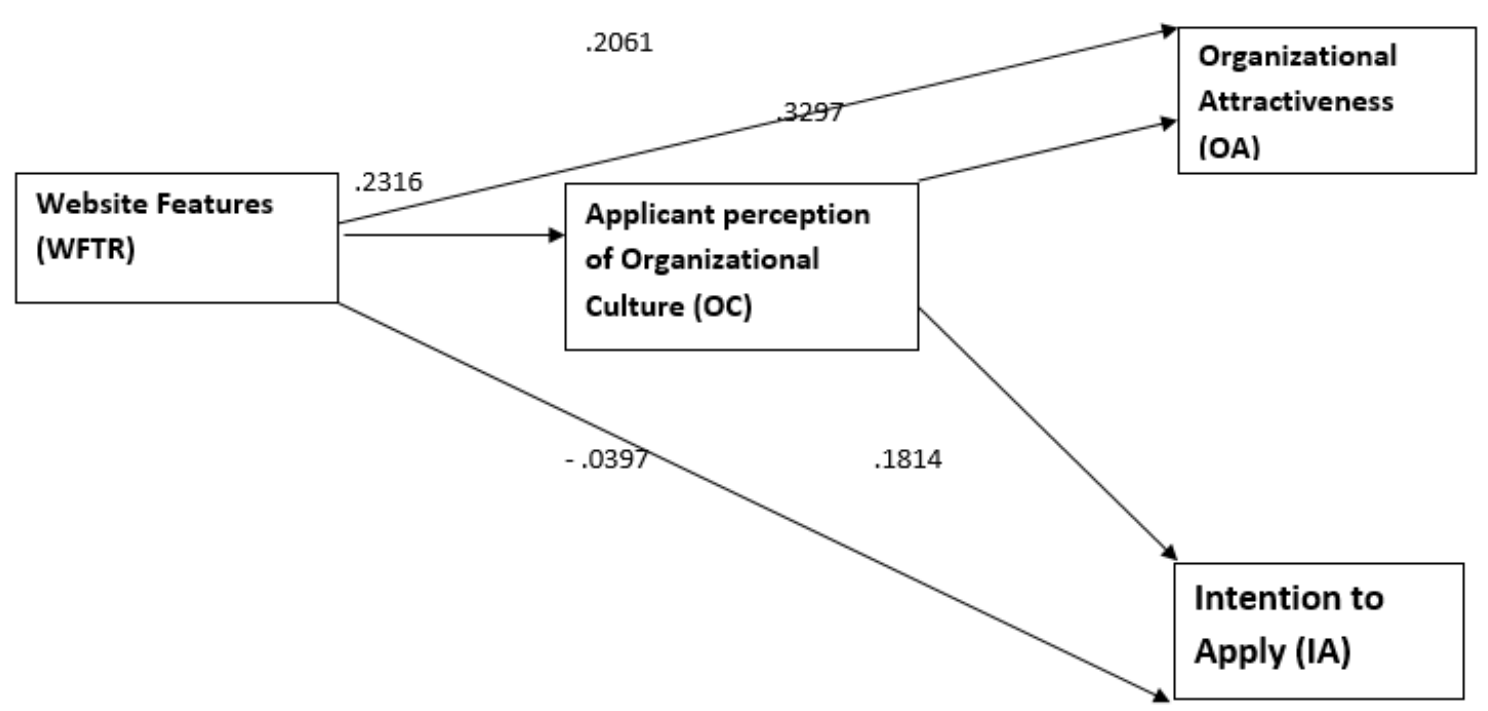

\section{Figure 1: Mediation Model}

The mediation test (Appendix 6-7) focuses specifically on Hypothesis 9, which assumes that applicant perception of organizational culture mediates the relationship between website features and organizational attractiveness.

The model is a good fit $(p=0.000)$. The regression coefficients show that a positive association exists between the website features and organizational attractiveness. The results show that website features significantly impact organizational attractiveness with a value within the acceptable range. Organizational culture partially mediates the relationship between website features and organizational attractiveness significantly with a p-value of 0.000 .

The perception of organizational culture and website features is illustrated with organizational attractiveness. The model of $\mathrm{R}$-Square regarding website features and applicant perception of corporate culture indicates that the organizational culture and website features are explained through intentions to apply.

The model illustrates that organizations can only achieve applicants' intentions to apply with the help of applicant perception of organizational culture. However, the direct effect of the website features on intentions to apply for the job is found insignificant. Applicant perception of organizational culture mediates the relationship between the variables website features and intentions to apply significantly; hence, full mediation exists with $\beta$ value and $p$-value within acceptable limits in this model.

\section{Discussions and Conclusion}

Organizations are increasingly adopting online recruitment channels in the age of industry 4.0. The traditional ways of recruitment are fading out. Companies are now increasingly relying on corporate websites, social media platforms, and online job boards in a quest to add value to human organizational capital. Research in the past has extensively focused on traditional recruitment techniques, whereas the outcomes of online recruitment have rarely been the focus of academic research in the business context. Against this backdrop, this study intends to provide practical implications for recruiters in the context of Pakistan.

With the emergence of the internet as a convenient and accepted source of communication, the use of e-recruitment is increasing day by day. It is becoming a popular source for recruitment in today's business environment. The literature and the study results 
highlight the various motivators and key factors that enhance the use of e-recruitment compared to traditional recruitment methods. The study results conclude that all of the motivators of e-recruitment have a positive and significant relationship with online recruitment practice except intention to apply as in Pakistan unemployment rate is high, and the applicants want to get the job. Further, the results also predict online recruitment as a dominant force being used in the foreseeable future. One of the key motivators that boost the use of online recruitment is cost-saving.

Though much research has been found in online recruitment and its effect on the viewer's perceptions of the organizational culture, this is the first study that tests this assumption. The contributions of the study area in the three different regions of the existing literature in this area. First, the study found that the participant's perception of the organization is affected by their online recruitment websites. In addition, the research also found that the viewer's perceptions of the organization can be enhanced through welldesigned and attractive organizational recruitment websites, both in general and as the prospective employer. So, the organizations should make active efforts to improve the various attributes of the e-recruitment websites in order to project a positive image over the prospective employees and other applicants.

The second contribution of the study is in line with the work of Philip W Braddy et al. (2003); Rozelle and Landis (2002); Zusman and Landis (2002) and other related studies in the field. The research found a moderately strong positive relationship between the usability aspect of the e-recruitment websites and the viewer's impressions of the organization. The findings also suggest a strong positive relationship between the participants' perceptions of the attractiveness of organizations' websites and how favorably they view these organizations. Thus, these findings support the predictions being made by signaling theory that any peripheral cues of a recruitment medium, which is a corporate recruitment website in the current study, directly affect how the applicant perceives the prospective organization.

Further, the research findings imply that in addition to forming favorable perceptions about the organization, it also directly links the job seekers to their inclination or preference to pursue a job in the prospective organization. Still, in Pakistan, the unemployment rate is high and impacts the applicant's perception, so the applicant wants a job regardless of positive or negative organizational attractiveness. Further, the current study also presents two key findings and the other research results via post-hoc exploratory analyses. First of all, the familiarity with the prospective organization has a moderately positive correlation with the participant's ratings towards the image and organizational attractiveness of the potential employer. This result is in accordance with the research being made by Turban (2001) and its findings, which revealed a positive relationship between the familiarity and attraction image of undergraduate students and their ratings of the local petrochemical firm. It provides practical implications for the companies that are serious in attracting the job seeker's attention through web recruitment while also reducing screening costs and enhancing the chances of good selection decisions. However, despite these recent research efforts, a fundamental gap in the Internet recruitment literature remains. Namely, while previous studies have examined the correlates of recruitment website features using crosssectional designs, researchers have not empirically demonstrated that viewers' impressions of an organization could be changed by viewing the organization's recruitment website. But the finding is contrary to the proclamation of Lemmink, Schuijf, and Streukens (2003) that there exists no relation between the familiarity and the organization image. Secondly, the study results also found a strong correlation between the participant's ratings of the organization on familiarity, image as an employer, and organizational attractiveness. So, both of these findings reinforce and exert the impression of the previous researches being done in the field of corporate recruitment e.g., Gatewood, Gowan, and Lautenschlager (1993) that the job seekers are more likely to be attracted towards the organizations that they regard positively as compared to the others.

\section{References}

Acikgoz, Y. (2019). Employee recruitment and job search: Towards a multi-level integration. Human resource management review, 29(1), 1-13. doi:https://doi.org/10.1016/j.hrmr.2018.02.009 
Agarwal, R., \& Venkatesh, V. (2002). Assessing a firm's web presence: a heuristic evaluation procedure for the measurement of usability. Information systems research, 13(2), 168-186. doi:https://doi.org/10.1287/isre.13.2.168.84

Ageeva, E., Foroudi, P., Melewar, T., Nguyen, B., \& Dennis, C. (2020). A holistic framework of corporate website favourability. Corporate Reputation Review, 23(3), 201-214. doi:https://doi.org/10.1057/s41299-019-00079-9

Aiman-Smith, L., Bauer, T. N., \& Cable, D. M. (2001). Are you attracted? Do you intend to pursue? A recruiting policy-capturing study. Journal of Business and psychology, 16(2), 219-237. doi:https://doi.org/10.1023/A:1011157116322

Ali, Q., Sheikh, M. F., \& Latif, B. (2021). How Much Does the Recruitment Channel Really Matter: Recruiters' and Applicants' Behaviors in the South Asian Context. Journal of Management and Research, 8(1), 1-22. doi:https://doi.org/10.29145/jmr/81/080101

Allen, D. G., Scotter, J. R. V., \& Otondo, R. F. (2004). Recruitment communication media: Impact on prehire outcomes. Personnel Psychology, 57(1), 143-171. doi:https://doi.org/10.1111/j.1744-6570.2004.tb02487.x

Banerjee, P., \& Gupta, R. (2019). Talent attraction through online recruitment websites: Application of web 2.0 technologies. Australasian Journal of Information Systems, 23, 1-23. doi:https://doi.org/10.3127/ajis.v23i0.1762

Braddy, P. W., Meade, A. W., \& Kroustalis, C. M. (2006). Organizational recruitment website effects on viewers' perceptions of organizational culture. Journal of Business and psychology, 20(4), 525-543. doi:https://doi.org/10.1007/s10869-005-9003-4

Braddy, P. W., Thompson, L. F., Wuensch, K. L., \& Grossnickle, W. F. (2003). Internet recruiting: The effects of web page design features. Social science computer review, 21(3), 374-385. doi:https://doi.org/10.1177/0894439303253987

Chang, E., \& Chin, H. (2018). Signaling or experiencing: Commitment HRM effects on recruitment and employees' online ratings. Journal of Business Research, 84, 175185. doi:https://doi.org/10.1016/j.jbusres.2017.11.002

Cober, R. T., Brown, D. J., Keeping, L. M., \& Levy, P. E. (2004). Recruitment on the Net: How do organizational Web site characteristics influence. Journal of management, 30(5), 623-646. doi:https://doi.org/10.1016\%2Fj.jm.2004.03.001

Cober, R. T., Brown, D. J., Levy, P. E., Cober, A. B., \& Keeping, L. M. (2003). Organizational web sites: Web site content and style as determinants of organizational attraction. International Journal of Selection and Assessment, 11(2-3), 158-169. doi:https://doi.org/10.1111/1468-2389.00239

Coyle, J. R., \& Thorson, E. (2001). The effects of progressive levels of interactivity and vividness in web marketing sites. Journal of advertising, 30(3), 65-77. doi:https://doi.org/10.1080/00913367.2001.10673646

Cyr, D., Head, M., \& Larios, H. (2010). Colour appeal in website design within and across cultures: A multi-method evaluation. International journal of human-computer studies, 68(1-2), 1-21. doi:https://doi.org/10.1016/j.ijhcs.2009.08.005

Fisher, C. D., Ilgen, D. R., \& Hoyer, W. D. (1979). Source credibility, information favorability, and job offer acceptance. Academy of Management Journal, 22(1), 94103. doi: https://doi.org/10.5465/255481

Gatewood, R. D., Gowan, M. A., \& Lautenschlager, G. J. (1993). Corporate image, recruitment image and initial job choice decisions. Academy of Management Journal, 36(2), 414-427. doi:https://doi.org/10.5465/256530

Kucherov, D., \& Tsybova, V. (2021). The contribution of e-recruitment practices to erecruitment outcomes in Russian companies. Measuring Business Excellence. doi:https://doi.org/10.1108/MBE-02-2021-0017

Lemmink, J., Schuijf, A., \& Streukens, S. (2003). The role of corporate image and company employment image in explaining application intentions. Journal of Economic Psychology, 24(1), 1-15. doi:https://doi.org/10.1016/S0167-4870(02)00151-4

Muduli, A., \& Trivedi, J. J. (2020). Recruitment methods, recruitment outcomes and information credibility and sufficiency. Benchmarking: An International Journal, 27(4), 1615-1631. doi:https://doi.org/10.1108/BIJ-07-2019-0312

O'Reilly III, C. A., Chatman, J., \& Caldwell, D. F. (1991). People and organizational culture: A profile comparison approach to assessing person-organization fit. Academy of Management Journal, 34(3), 487-516. doi:https://doi.org/10.5465/256404 
Pfieffelmann, B., Wagner, S. H., \& Libkuman, T. (2010). Recruiting on corporate web sites: Perceptions of fit and attraction. International Journal of Selection and Assessment, 18(1), 40-47. doi:https://doi.org/10.1111/j.1468-2389.2010.00487.x

Puncheva-Michelotti, P., Hudson, S., \& Jin, G. (2018). Employer branding and CSR communication in online recruitment advertising. Business Horizons, 61(4), 643651. doi:https://doi.org/10.1016/j.bushor.2018.04.003

Robbins, S. S., \& Stylianou, A. C. (2003). Global corporate web sites: an empirical investigation of content and design. Information \& Management, 40(3), 205-212. doi:https://doi.org/10.1016/S0378-7206(02)00002-2

Rozelle, A. L., \& Landis, R. S. (2002). An examination of the relationship between use of the Internet as a recruitment source and student attitudes. Computers in Human Behavior, 18(5), 593-604. doi:https://doi.org/10.1016/S0747-5632(02)00002-X

Scheu, C., Ryan, A., \& Nona, F. (1999). Company web sites as a recruiting mechanism: What influences applicant impressions. Paper presented at the 14th annual meeting of the Society for Industrial and Organizational Psychology, Atlanta, GA.

Selden, S., \& Orenstein, J. (2011). Government E-Recruiting Web Sites: The influence of e-recruitment content and usability on recruiting and hiring outcomes in US state governments. International Journal of Selection and Assessment, 19(1), 31-40. doi:https://doi.org/10.1111/j.1468-2389.2011.00532.x

Sivertzen, A.-M., Nilsen, E. R., \& Olafsen, A. H. (2013). Employer branding: employer attractiveness and the use of social media. Journal of Product \& Brand Management, 22(7), 473-483. doi:https://doi.org/10.1108/JPBM-09-2013-0393

Sylva, H., \& Mol, S. T. (2009). E-Recruitment: A study into applicant perceptions of an online application system. International Journal of Selection and Assessment, 17(3), 311-323. doi:https://doi.org/10.1111/j.1468-2389.2009.00473.x

Thompson, L. F., Braddy, P. W., \& Wuensch, K. L. (2008). E-recruitment and the benefits of organizational web appeal. Computers in Human Behavior, 24(5), 2384-2398. doi:https://doi.org/10.1016/j.chb.2008.02.014

Turban, D. B. (2001). Organizational attractiveness as an employer on college campuses: An examination of the applicant population. Journal of Vocational Behavior, 58(2), 293-312. doi:https://doi.org/10.1006/jvbe.2000.1765

Van der Heijden, H. (2003). Factors influencing the usage of websites: the case of a generic portal in The Netherlands. Information \& Management, 40(6), 541-549. doi:https://doi.org/10.1016/S0378-7206(02)00079-4

Zusman, R. R., \& Landis, R. S. (2002). Applicant preferences for web-based versus traditional job postings. Computers in Human Behavior, 18(3), 285-296. doi:https://doi.org/10.1016/S0747-5632(01)00046-2 